\title{
Fe Elementinin Kristal ve Camsı Faza Dönüşümünün Hidrostatik Basınç Altında İncelenmesi: Moleküler Dinamik Benzetim Çalışması
}

\section{The Investigations Under the Hydrostatic Pressure of the Crystal and Glass Phase Transformation Temperatures of the Fe Element: A Molecular Dynamic Simulations Study}

\begin{abstract}
Sefa Kazanç ${ }^{1}$, Canan Aksu Canbay ${ }^{2 *}$
Geliş / Received: 02/12/2020

Revize / Revised: 02/02/2021

Kabul / Accepted: 19/02/2021

$\overline{\text { ÖZ }}$

$\mathrm{Bu}$ çalışmada moleküler dinamik benzetim yöntemi ile 4000 atomdan oluşan sıvı Fe model sistemi $0 \mathrm{GPa}, 5 \mathrm{GPa}, 7$ GPa basınç değerleri altında $1 \times 10^{12} \mathrm{~K} / \mathrm{s}$ ve $1 \times 10^{13} \mathrm{~K} / \mathrm{s}$ soğutma hızları ile soğutularak kristal ve camsı geçiş sıcaklıklarının yapı içerisinde oluşturdukları farklı birim hücreli atomik kümelenmeler belirlenmeye çalışıldı. Atomlar arası etkileşmelerin hesaplanmasında çok cisim etkileşmelerini temel alan Gömülmüş Atom Metodu kullanıldı. Basınç artışının, sıvı fazdan soğutulan Fe deki kristal ve amorf yapıların oluşumuna ve bu yapılara geçiş sıcaklıkları üzerinde etkili olduğu görüldü. Kristal ve amorf faza geçiş $\left(\mathrm{T}_{\mathrm{g}}\right)$ sıcaklıklarının belirlenmesi için birim atom başına bağlanma enerjisi ve Wendt-Abraham parametresinden yararlanıldı. Ayrıca sıvı fazdan katılaşma esnasında Fe model sistemde oluşan farklı birim hücre yapılarının yüzdesi Ackland-Jones analiz yöntemi kullanılarak belirlendi.
\end{abstract}

Anahtar Kelimeler- Kristal ve Camsı Geçiş Sıcaklı̆̆ı, Moleküler Dinamik Benzetimi, Gömülmü̈s Atom Metodu, Hızlı Soğutma

\begin{abstract}
In this study, the liquid Fe model system, which consists of 4000 atoms with molecular dynamic simulation method, is cooled under $0 \mathrm{GPa}, 5 \mathrm{GPa}, 7 \mathrm{GPa}$ pressure values with $1 \times 10^{12} \mathrm{~K} / \mathrm{s}$ and $1 \times 10^{13} \mathrm{~K} / \mathrm{s}$ cooling rates, and the different unit cell atomic atomic structure formed by crystal and glass transition temperatures in the structure. clusters were tried to be determined. The Embedded Atom Method, which is based on many body interactions, was used in the calculation of interactions between atoms. It was seen that the pressure increase had an effect on the formation of crystal and amorphous structures in Fe cooled from the liquid phase and the transition temperatures to these structures. Binding energy per unit atom and the Wendt-Abraham parameter were used to determine the crystal and amorphous phase transition $\left(\mathrm{T}_{\mathrm{g}}\right)$ temperatures. In addition, the percentage of different unit cell structures formed in the Fe model system during solidification from the liquid phase was determined using the Ackland-Jones analysis method.
\end{abstract}

Keywords- Crystal and Glass Transition Temperature, Molecular Dynamics Simulation, Embedded Atom Method, Rapid Cooling

\footnotetext{
1İletişim: skazanc@firat.edu.tr (https://orcid.org/0000-0002-8896-8571)

Matematik ve Fen Bilimleri Eğitimi Bölümü, Fırat Üniversitesi, Eğitim Fakültesi, Elazığ, Türkiye

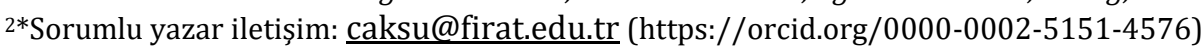

Fizik Bölümü, Fırat Üniversitesi, Fen Fakültesi, Elazı̆ğ, Türkiye
} 


\section{GíRiș}

Sıcaklık ve basınç maddelerin fazları, termodinamik ve fiziksel özellikleri üzerinde etkili önemli iki faktördür. Bir malzemenin sıvı fazdan farklı hızlarda soğutulması onun farklı yapılarda olmasında önemli bir rol oynar. Metal erime sıcaklığından düşük sıcaklık bölgesine soğutulduğunda, soğutma hızına bağlı olarak ya kristal ya da amorf yapıda olabilir [1-4]. Eğer sıvı fazdan soğutma hızı kritik soğutma hızından yeteri kadar büyük $\left(10^{6}\right.$ $10^{12} \mathrm{~K} / \mathrm{s}$ ) ise kristal fazın homojen çekirdeklenmesi önlenebilir ve yarı kararlı amorf yapı oluşur [5, 6]. 1960 yılında Duwez ve arkadaşları sıvı Au75Si25 alaşımını hızlıca soğutarak ilk camsı metali ürettiler [7]. Aşınma, yüksek korozyon dayanımları, sertlik ve üstün manyetiklik gibi özelliklerinden dolayı metalik camsılar ilgi çekmektedirler $[8,9]$. Deneysel olarak metalik camsıların üretimi için damlacık soğutma ve piston örs yöntemi [10], üfleme yöntemi [11], levitasyon ergitme ve döküm [12], ögütme [13], mekanik alaşımlama [14], laser ve elektron ile bombardıman [15] gibi yöntemler kullanılmaktadır. Bununla birlikte deneysel çalışmalarda camsı dönüşümün doğasının belirlenmesi oldukça zor bir iştir.

Fe'in krsitolografik yapısı sıcaklığa bağlı olarak farklı yapılar göstermektedir. Fe için soğutma esnasında meydana gelen fcc yapıdan bcc yapıya katı-katı faz dönüşümü (martensitik faz dönüşümü) oldukça önemlidir [16]. Malzemelerin makroskobik ve mikroskobik özellikleri üzerinde faz geçişlerinin önemli bir etkisi vardır. Fe'in belirlenen faz bölgesinde tutulması 1sıtma veya soğutma işlemleri ile sağlanmakta ve istenilen özellikler belirli sınırlar içinde kalmaktadır [17-20]. Fe'in faz diyagramının karmaşık bir yapıya sahip olması manyetik özelliklerinden dolayıdır ve iletim elektronlarını ve dolayısıyla bağlanma özelliklerini etkilemektedir [21, 22]. Bununla birlikte benzetim yöntemleri Fe elementinin modellenmesi ve faz dönüşümlerinin belirlenmesinde MD benzetim yöntemi etkili bir şekilde kullanılmaktadır [23-25]. Son yıllarda Fe'in modellenmesi için birçok yeni potansiyel fonksiyonu geliştirilmiştir [26-30].

Moleküler Dinamik (MD) benzetim yöntemleri atomik ölçekte sıvı fazdan kristal ve amorf yapıların oluşumunun incelenmesinde kullanılan önemli yöntemlerdendir. MD benzetim yöntemi N parçacıktan oluşan atomik sistemin Lagrange fonksiyonundan elde edilen hareket denklemlerinin uygun bir sayısal algoritma ile çözülerek faz uzayındaki yörüngelerinin belirlenmesini amaçlar [31,32]. Modellenecek sistemden gerçeğe en yakın benzetim sonuçlarının elde edilmesinde ana faktör atomlararası etkileşmelerin belirlenmesi için seçilen potansiyel enerji fonksiyonudur. Literatürde farklı metal ve alaşım sistemlerinin modellenmesi için kullanılan çok sayıda potansiyel enerji fonksiyonu bulunmaktadır. Daw ve Baskes [33] tarafindan geliştirilen ve çok cisim etkileşmelerini içeren Gömülmüş Atom Metodu MD benzetimlerinde tek atomlu ve alaşım sistemlerinin modellenmesinde en çok kullanılan potansiyel fonksiyonudur. Bu potansiyel fonksiyonunun Vother-Chen [34], Finnis-Sinclair [35] ve Sutton-Chen [36] tarafından ikili etkileşme, gömme fonksiyonu ve yük yoğunluğunun farklı şekilde ifade edilmesi sonucu geliştirilmiş farklı yapıları bulunmaktadır. İlk prensip metotları (fïst principles) kuantum etkileşmeleri içerdiğinden incelenecek sistemin gerçeğe daha yakın olarak modellenmesine imkan sağlamaktadır. Bununla birlikte bu yöntem düşük parçacık sayısı ve çok sayıda işlemci içeren sistemler gerektirmektedir.

Bu çalışmada moleküler dinamik benzetim yöntemi kullanılarak 4000 atomdan oluşan sıvı Fe model sistemi $0,5 \mathrm{GPa}$ ve $7 \mathrm{GPa}$ basınç değerleri altında farklı soğutma hızları ile soğutularak kristal ve camsı geçiş sıcaklıkları ve bu geçişler esnasındaki yapısal değişimler incelendi. Çalışmalarda LAMMPS açık kaynak kodlu moleküler dinamik benzetim programı kullanıldı. Soğutma hızının model yapının kristal veya amorf faza geçişinde etkili olduğu ve uygulanan basıncın dönüşüm sıcaklıklarını değiştirdiği belirlenmiştir. Kristal faza geçiş sıcaklığı kohesif enerjideki süreksizlikten, camsı geçiş sıcaklığı Wendt-Abraham parametresinden belirlenmiştir. Soğutma işlemi sonucu meydana gelen yapısal geçişlerin belirlenmesinde radyal dağılım fonksiyonu ve Ackland-Jones analiz yöntemi kullanılmıştır.

\section{MATERYAL VE METOT}

$\mathrm{N}$ atomdan meydana gelen parçacıklar topluluğunun hareket denklemlerini elde etmek için kullanılan Lagrange fonksiyonu;

$$
\mathrm{L}_{\mathrm{PR}}\left(\mathrm{r}^{\mathrm{N}}, \dot{\mathrm{r}}^{\mathrm{N}}, \mathrm{h}, \dot{\mathrm{h}}\right)=\frac{1}{2} \sum_{\mathrm{i}=1}^{\mathrm{N}} \mathrm{m}_{\mathrm{i}}\left(\dot{\mathrm{s}}_{\mathrm{i}}^{\mathrm{t}} \mathrm{G} \dot{\mathrm{s}}_{\mathrm{i}}\right)-\sum_{\mathrm{i}=1}^{\mathrm{N}} \sum_{\mathrm{j}>\mathrm{i}}^{\mathrm{N}} \phi\left(\left|\mathrm{h} \mathrm{s}_{\mathrm{ij}}\right|\right)+\frac{1}{2} \mathrm{MTr}\left(\dot{\mathrm{h}}^{\mathrm{t}} \dot{\mathrm{h}}\right)-\mathrm{P}_{\mathrm{ext}} \mathrm{V}
$$

şeklinde verilmektedir. Burada $s_{i}, i$ parçacığının koordinatını, h matrisi MD hücre eksenlerini, $\boldsymbol{G}$ metrik tensörü, $m_{i}, i$ parçacığının kütlesini, $P_{e x t}$ dış basıncı ve $V$, MD hücre hacmini ifade etmektedir. $M$ ise MD hücresinin 
kütlesini temsil eden keyfi bir sabittir. Lagrange fonksiyonundan parçacıklar ve MD hücre hacmi için elde edilen hareket denklemleri aşağıdaki şekildedir.

$$
\begin{aligned}
& \ddot{\mathbf{s}}_{i}=-\frac{1}{m_{i}} \mathbf{F}_{i}-\mathbf{G}^{-1} \dot{\mathbf{G}} \dot{\mathbf{s}}_{\boldsymbol{i}} \\
& \ddot{\mathbf{h}}=M^{-1}\left(\Pi-\mathbf{I} P_{\text {ext }}\right)
\end{aligned}
$$

burada $\sigma=V\left(\mathbf{h}^{\mathrm{t}}\right)^{-1}$ olarak verilmekte vemikroskobik zor tensörü $\boldsymbol{\Pi}$ aşağıdaki şekilde ifade edilmektedir [37, 38].

$$
\boldsymbol{\Pi}=V^{-1}\left[\sum_{i=1}^{N} m_{i} \boldsymbol{v}_{i} \cdot \boldsymbol{v}_{i}-\sum_{i=1}^{N} \sum_{j>i}^{N} \frac{F_{i j}}{r_{i j}} \mathbf{r}_{i} \cdot \mathbf{r}_{i}\right]
$$

Bu çalışmada büyük ölçekli atomic/moleküler kitlesel paralel simülatör (Large-scale Atomic/Molecular Massively Parallel Simulator-LAMMPS) açık kaynak kodlu moleküler dinamik benzetim yöntemi kullanıldı [39].Başlangıç konumları olarak $4000 \mathrm{Fe}$ atomu fcc örgü noktalarına yerleştirildi. Parçacık sayısının, basıncın ve sıcaklığın sabit tutulduğu NPT istatistiksel topluluğu kullanılarak Fe atomlarının ilk hızları Maxwell-Boltzman hız dağılımına uygun olacak şekilde rasgele belirlendi. Periyodik sınır şartları MD hesaplama hücresinin [100], [010] ve [001] doğrultuları boyunca uygulandı. Verlet Algoritmasının hız yapısı hareket denklemlerinin sayısal çözümü için kullanıldı. Potansiyel etkileşmesinin kesilim mesafesi olan cut-off değeri $2 \mathrm{a}_{\mathrm{Fe}}$ olarak seçildi. MD zaman adımı hesaplamalarda 1 fs olarak alınd.

\section{A. Potansiyel Enerji Fonksiyonu}

Modelleme çalışmalarında atomlararası etkileşmeleri veren potansiyel enerji fonksiyonları malzemelerin özelliklerini gerçeğe en yakın olarak belirlemede oldukça önemlidir. Gömülmüş Atom Metodunda (GAM) $N$ atom içeren bir hesaplama hücresinde sistemin toplam enerji ifadesi [40, 41];

$$
E_{T}=\frac{1}{2} \sum_{\substack{i, j \\(i \neq j)}} \emptyset\left(r_{i j}\right)+\sum_{i}^{N} F\left(\bar{\rho}_{l}\right)
$$

şeklinde verilmektedir. İkili etkileşme fonksiyonu atomlar arası itici etkileşmeleri ve gömme enerjisi fonksiyonu da çekici etkileşmeleri ifade etmektedir. Farklı sistemleri modellemek için GAM'ın farklı türleri literatürde bulunmaktadır [40, 41]. Birçok potansiyel fonksiyonu Fe elementin modelleyebilmek için geliştirilmiştir [42-44]. Bununla birlikte Fe elementinin bütün özelliklerini modelleyebilecek bir potansiyel fonksiyonu yoktur. Bu çalışmada Fe elementi için Ackland ve arkadaşları tarafından geliştirilen GAM potansiyeli ve deneysel verilere yeniden fit edilmesinden elde edilen parametreleri kullanıldı [44].

Maddelerin fazlarını belirlemek için birçok analiz yöntemi bulunmaktadır [45-47]. En çok kullanılan analiz tekniklerinden biri Radyal Dağılım Fonksiyonu (RDF) dur. Seçilen bir $i$ atomundan bir $r$ uzaklığında $\Delta r$ küre kabuğunda bulunan atomların sayısı $n(r)$ olmak üzere $g(r)$ radyal dağılım fonksiyonu;

$$
g(r)=\left\langle\frac{V}{N^{2}} \frac{\sum_{i} n_{i}(r)}{4 \pi r^{2} \Delta r}\right\rangle
$$

şeklinde verilir [48].

fcc, hcp, bcc gibi sıkı paket yapıların MD hücresi içerisinde tespit edilmesi benzetim çalışmalarında önemli problemlerden biridir. Katı fazdaki yapıların belirlenmesi için birçok sayısal analiz metodu geliştirilmiştir. $\mathrm{Bu}$ yöntemlerin amacı her bir parçacığa bir yapısal tür atamaktır. Ayrıca bu yöntemler yerel bir yapıyı idealleştirilmiş bir yapıyla eşleştirerek ne kadar yakın olduklarını belirlemeye çalışır. Merkez simetri parametre analizi (centrosymmetry paramatre analysis), bağ-yönelim analizi (bond-order analysis), genel yakın komşu analizi (common neighbohr analysis), bağ açı analizi (bond-angle analysis), Voronoi analizi, Honeycutt-Andersen metodu gibi MD benzetim çalışmalarında kullanılan yapı karakterizasyon yöntemleri vardır. Ackland-Jones (A-J) analiz yöntemi de bunlardan birisidir. Bu yöntem her bir atomu çevreleyen yerel komşuluğun açısal dağılımına odaklanır. Bu çalışmada MD hücresi içerinde var olan bu birim hücrelerin yapı içerisinde dağılım yüzdeleri Ackland-Jones analiz yöntemi [47] kullanılarak belirlenmeye çalışıldı. 


\section{BULGULAR VE TARTIŞMA}

Bu çalışmada Fe model sisteminin sıvı fazdan $0,5 \mathrm{GPa}$ ve $7 \mathrm{GPa}$ basınç değerleri altında, $1 \times 10^{13} \mathrm{~K} / \mathrm{s}$ ve $1 \times 10^{12} \mathrm{~K} / \mathrm{s}$ soğutma hızları ile soğutulması sonucu meydana gelen kristal ve camsı faz geçişleri incelendi. Fe atomlarının başlangıç konumları olarak fcc örgü noktaları seçildi. 4000 atomdan meydana gelen model MD hücresi $300 \mathrm{~K}$ sıcaklık değerinde $1 \times 10^{5}$ integrasyon adımı dengeletildi. İlk 10000 adım için sıcaklık, kohesif enerji ve hacim değişimi Şekil 1 de görülmektedir. İlk 1000 MD adımında verilen niceliklerde bir artış meydana gelmektedir. 2800. adıma kadar niceliklerde herhangi bir değişim gözlenmemekte ve model sistem başlangıç yapısı olan fcc yapıda kararlı kalmaktadır. Model sistemin fcc yapıda olduğu Şekil 2 de 1000, 2000 ve 2800. integrasyon adımlarında elde edilen RDF eğrilerinden açıkça görülmektedir. 2800. integrasyon adımında verilen niceliklerde yeniden bir değişim görülmekte, sıcaklık değerinde bir artış buna karşılık, kohesif enerji $\left(E_{c}\right)$ ve hacim değerlerinde bir azalma meydana gelmektedir. Bu değişim sonucunda sabit sıcaklıkta fcc yapıdaki model sistemin daha kararlı olan düşük enerjili bcc faza dönüştüğü Şekil 2 de 3000. adımda elde edilen radyal dağıl fonksiyonundan da görülmektedir. Nicelikler 4400. MD integrasyon adımında tekrar dengeye ulaşmakta ve böylece kararlı bcc denge fazı elde edilmiş olmaktadır. Şekil 2 de 10000. adımda elde edilen RDF eğrisinden de bu durum açıkça görülmektedir. Deneysel olarak $300 \mathrm{~K}$ sıcaklıkta Fe in bcc birim hücreli $\alpha$ fazında olduğu bilinmektedir [49]. fcc örgü noktalarına yerleştirilen Fe atomlarından oluşan model MD hücresinin aynı sıcaklık değerinde iterasyonun başlangıcından kısa bir süre sonra bcc birim hücreli yapıya dönüşmesi atomlararası etkileşmeleri belirlemede kullanılan potansiyel enerji fonksiyonunun Fe sistemini gerçeğe yakın bir şekilde modelleyebileceğini göstermektedir.

Erime sıcaklığını belirlemek amacıyla model Fe sisteminin sıcaklık değeri $300 \mathrm{~K}$ den $2200 \mathrm{~K}$ e $100 \mathrm{~K}$

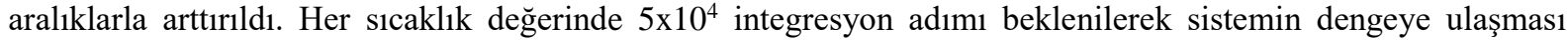
sağlandı. Erime sıcaklığının daha hassas belirlenmesi amacı ile $1700 \mathrm{~K}$ den sonra sıcaklık artışı $50 \mathrm{~K}$ aralıklarla gerçekleştirildi. Sıcaklığa karşı kohesif enerjinin (Ec) değişimi Şekil 3 de verilmiştir. Model sistemin sıcaklığı $1850 \mathrm{~K}$ e ulaştığında enerjide bir süreksizlik meydana geldiği açıkça görülmektedir. Kohesif enerjide meydana gelen bu süreksizlik yapının sıvı faza geçişinin bir göstergesidir [50]. Benzetim çalışmamızdan sistemin erime sıcaklığı $1875 \pm 25 \mathrm{~K}$ olarak tespit edilmiştir. Fe elementinin erime sıcaklığı deneysel olarak $1809 \mathrm{~K}$ değerindedir [19]. Buradan elde ettiğimiz erime sıcaklık değerinin deneysel değerlerle uyum içerisinde olduğunu söyleyebiliriz. Bununla birlikte erime sıcaklığından önce kohesif enerjide iki farklı sıcaklık değerinde küçükte olsa değişimler gözlenmektedir. Enerjideki bu artış yapısal bir faz dönüşümüne işaret etmektedir. $1200 \mathrm{~K}$ de model sistemde $\mathrm{bcc} \rightarrow \mathrm{fcc}$ ve $1750 \mathrm{~K}$ de ise $\mathrm{fcc} \rightarrow$ bcc katı-katı faz dönüşümünün meydana geldiği söylenebilir [51].

Model Fe sistemi 0, 5 ve $7 \mathrm{GPa}$ basınç değerleri altında $2200 \mathrm{~K}$ den $300 \mathrm{~K}$ e $1 \times 10^{13} \mathrm{~K} / \mathrm{s}$ soğutma hızı ile soğutuldu. Soğutma işlemi esnasında meydana gelen yapısal değişimleri belirlemek için Şekil 4(a-c) de verilen RDF eğrilerinden yararlanıldı. $2200 \mathrm{~K}$ sıcaklık değerinde bütün basınç değerleri için sistemin sıvı fazda olduğu RDF eğrilerinden açıkça görülmektedir. Soğutma işlemi esnasında $1400 \mathrm{~K}$ sıcaklık değerine ulaşıldığında, üç basınç değeri içinde model sistemin hala sıvı fazda olduğu görülmektedir. Bununla birlikte bu durum aşırı soğutulmuş bir sıvı olarak ifade edilmektedir. Sıcaklık $0 \mathrm{GPa}$ basınç için $1000 \mathrm{~K}, 5 \mathrm{GPa}$ için $1100 \mathrm{~K}$ ve $7 \mathrm{GPa}$ için $1300 \mathrm{~K}$ değerine indiğinde RDF eğrilerinin ikinci pikinde bir çökme Şekil 3(a-c) de açıça görülmektedir. İkinci pikteki bu çökme RDF eğrisinde amorf yapının genel bir özelliği olarak bilinmektedir [52]. Soğutma işlemi tamamlanıp sıcaklık $300 \mathrm{~K}$ değerine ulaştığında model sistemin her üç basınç değeri içinde amorf yapıda olduğu belirlenmiştir. Sıcaklığın azalmasıyla birlikte RDF eğrilerindeki pik şiddetleri artmaktadır. Bu artışın sebebinin, sıcaklığın azalmasıyla katılaşma esnasında en yakın komşu koordinasyonun artması olduğu söylenebilir.

Wendt-Abraham parametresinin sıcaklığa bağlılığı camsı dönüşümün bir göstergesidir. MD benzetim çalışmalarında camsı geçiş sıcaklığını belirlemek için $\mathrm{g}_{\min } / \mathrm{g}_{\max }$ olan Wendt-Abraham parametresi kullanıldı. Burada $g_{\max }$ RDF eğrisindeki ilk maksimum değeri, $g_{\text {min }}$ ise ilk minimum değeri göstermektedir. Şekil 5 te $0 \mathrm{GPa}$ basınç değeri altında model sistem için sıcaklığa karşı $\mathrm{g}_{\min } / \mathrm{g}_{\max }$ değişimi verilmiştir. Camsı yapının oluşumu şekildeki eğrinin eğiminde bir değişime sebep olur. Şekil 5 ten görüldüğü gibi farklı eğimli iki doğrusal çizgi vardır ve $T_{g}$ sıcaklığı bu iki doğrusal çizginin kesiştiği nokta olarak belirlenmiştir. Model sistem için 0 GPa basınç altında bu sıcaklık değeri $1050 \mathrm{~K}$ olarak bulunmuştur. Bununla birlikte Şekil 6 da $0,5 \mathrm{GPa}$ ve $7 \mathrm{GPa}$ basınç değerleri altında sıcaklığa karşı $\mathrm{g}_{\min } / \mathrm{g}_{\max }$ değişimi birlikte verilmiş ve aynı yöntemle $\mathrm{T}_{\mathrm{g}}$ sıcaklığ $5 \mathrm{GPa}$ basınç değeri için $1100 \mathrm{~K}$ ve $7 \mathrm{GPa}$ için $1350 \mathrm{~K}$ olarak belirlenmiştir. Basıncın artması, model sistemdeki sıvı atomların birbirlerini sıkıştırmasına ve çok daha yüksek bir yoğunluğa ve daha az miktarda serbest hacme sahip olmasına neden 
olmuştur. Bundan dolayı, basınçtaki artış nedeniyle parçacıkların hareketleri azalmış ve $T_{\mathrm{g}}$ nin değeri artırmıştır [53].

Çalışmada farklı soğutma hızları sonucu elde edilen MD hücresindeki farklı yapıların gelişimi bağ açısı dağılım fonksiyonlarını kullanan Ackland-Jones (A-J) metodu ile yapıldı. Analizler ve görselleştirme için OVITO yazılım programından yararlanıldı [54]. Ackland- Jones metodu model sistem içerisindeki kusursuz yapıdaki birim hücrelerin belirlenmesinin yanısıra, termal dalgalanmalardan ve elastik gerilmelerden kaynaklanan küçük bozulmalara sahip birim hücrelerinde analizde kullanılır. Bu yöntemde bir algoritma ile her atomun ait olduğu bölgesel yapılara karar verilir. Her yapı belirli bir açısal dağılım fonksiyonuna sahip olduğundan bu metot yüksek sıcaklıklarda bile fcc ve hcp yapıları arasındaki farkı belirlememizi sağlar [45-47]. Bu yöntemde farklı birim hücre yapıları farklı renklerle gösterilmektedir. $1 \times 10^{13} \mathrm{~K} / \mathrm{s}$ soğutma hızı için $0 \mathrm{GPa}$ basınç değerinde 2200 den $300 \mathrm{~K}$ e kadar her $100 \mathrm{~K}$ sıcaklık değerinde A-J metodu ile yapı içerindeki fcc, bcc, hcp ikosahedral ve bunların dişındaki diğer yapıların yüzde değerleri Şekil 7 de verilmiştir. A-J metodu her atomu çevreleyen bölgesel atomların açısal dağılımına odaklanarak bu yapıları bilinen fcc, hcp, bcc ve ikosahedral yapılarla karşılaştırır. Seçilen atom için belirlenen yapılar bu yapılarla uyum sağlamıyorsa diğer seçeneği işaretlenir. Sıvı fazdaki model yapı için diğer seçeneğinin en yüksek değerde olacağını tahmin etmek çok zor değildir ve Şekil 7 de tüm sıvı fazı içerisinde \% 67.5 lik bir orana sahip olduğu açıkça görülmektedir. fcc ve ikosahedral yapılar tüm sistem içerisinde sırasıyla \% 0.9 ve \% 0.8 değerlerle neredeyse sıfıra yakınken bcc ve hcp yapıların yüzdeleri sirasıyla \%13.8 ve \% 16.9 dur. Sıcaklığın düşmesiyle tanımlı olmayan yapılar (diğer) azalırken tanımlı diğer yapıların (fcc, bcc, hcp ve ikosahedral) sistem içerisindeki yüzdesi giderek artmaya başlamıştır. Bu basınç değerinde $1050 \mathrm{~K}$ olan camsı geçiş sıcaklığında yüzdelerdeki değişim durumları Şekil 7 de açıkça görülmektedir. $300 \mathrm{~K}$ sıcaklık değerine ulaşıldığında en yüksek artış bcc de olmak üzere diğer tanımlı yapıların model sistem içerisindeki yüzdeleri artarken tanımsız olan yapıların yüksek sıcaklık değerlerindeki oranına göre oldukça düşük bir değere sahip olduğu belirlenmiştir. Bununla birlikte bütün basınç değerleri için tanımlı olan yapıların sistem içerisindeki yüzdelerinin sıcaklıkla değişimleri Şekil 8 de verilmiştir. Basıncın artması model sistem içerisinde $300 \mathrm{~K}$ sicaklık değerinde ikosahedral yapıların azalmasına sebep olurken bcc ve fcc yapıların yüzdesinde bir atış görülmektedir. Artan basınç $300 \mathrm{~K}$ sıcaklık değerinde hcp yapıda fazla bir değişime sebep olmamıştır.

Benzetim yönteminden elde edilen amorf faz yapılarının A-J yöntemi ile analiz edilmesinden her bir atomun etrafındaki bölgesel atomik yerleşimlerin ağırlıklı olarak kristal benzeri (quasi-krsital) yapılarda olduğu söylenebilir. Camsı geçişin kristal benzeri atomların uzun mesafelerde bir araya gelmesinden oluştuğu düşünülmektedir. Düzensiz sistemlere uygulanan A-J analiz yöntemine göre, yani sıvı fazdan amorf faza geçişte, her bir atomun etrafındaki bölgesel atomik yığılmaların kristal benzeri bir yapıya dönüştüğü ve bu bölgesel yapıların amorf fazda birbirine bağlı hale geldiği söylenebilir. Bu durum amorf yapının bir özelliği olarak düşünülebilir. Amorf faza geçiş bölgesinde sıcaklığın azalmasıyla atomik küme boyutunun daha küçük kümelerin birleşmesiyle büyüdüğü ve bu durumun amorf faza geçişte önemli bir akışkanlık artışının başlangıcının kaynağ olduğu söylenebilir [55].

Şekil 9(a-c) de model Fe sisteminin $1 \times 10^{12} \mathrm{~K} / \mathrm{s}$ soğutma hızı ile 0,5 ve $7 \mathrm{GPa}$ basınç değerleri altında soğutulması esnasında elde edilen RDF eğrileri verilmiştir. Bütün basınç değerleri için $2200 \mathrm{~K}$ sıcaklık değerinde sistemin sıvı fazda olduğu RDF eğrilerinden açıkça görülmektedir. $1400 \mathrm{~K}$ sıcaklık değerinde belirlenen RDF eğrileri incelendiğinde üç basınç değeri içinde model sistemin aşırı soğutulmuş bir sıvı durumunda olduğu söylenebilir. Sıcaklık $0 \mathrm{GPa}$ basınç için $1000 \mathrm{~K}, 5 \mathrm{GPa}$ için $1200 \mathrm{~K}$ ve $7 \mathrm{GPa}$ basınç değeri için $1300 \mathrm{~K}$ değerine indiğinde RDF eğrilerinin ikinci pikinde bir çökme Şekil 9(a-c) de açıkça görülmektedir. Sıcaklığın azalmasıyla piklerin daha belirginleştiği ve soğutma işlemi tamamlanıp sıcaklık $300 \mathrm{~K}$ değerine ulaştığında model sistemin her üç basınç değeri içinde bcc kristal yapıda olduğu belirlenmiştir. Sıcaklığın azalmasıyla birlikte RDF eğrilerindeki pik şiddetlerindeki artış açıkça görülmektedir.

Şekil 10 da sıvı fazdan $1 \times 10^{12} \mathrm{~K} / \mathrm{s}$ soğutma hızı ile soğutulan model sistem için farklı basınç değerlerinde sıcaklığa karşı kohesif enerjideki değişim verilmiştir. Her üç basınç değeri içinde belirli sıcaklıklarda kohesif enerjinin süreksizlik gösterdiği sıcaklık bölgeleri görülmektedir. $0 \mathrm{GPa}$ için $950 \mathrm{~K}, 5 \mathrm{GPa}$ için $1050 \mathrm{~K}$ ve $7 \mathrm{GPa}$ için $1150 \mathrm{~K}$ değerlerinde görülen bu süreksizlik yapının sıvı fazdan kristal faza dönüşüm sıcaklığında $\left(\mathrm{T}_{\mathrm{c}}\right)$ meydana gelmektedir. Artan basıncın kristal faza geçiş sıcaklığını da arttırdığı açık bir şekilde görülmektedir.

Model Fe sisteminin sıvı fazdan $1 \times 10^{12} \mathrm{~K} / \mathrm{s}$ soğutma hızı ile soğutulması sonucu MD hücresindeki farklı kristal yapıların gelişimini karakterize etmek için kullanılan A-J metodundan 0 GPa basınç değeri için yapı içerisinde belirlenen fcc, bcc, hcp ikosahedral ve bunların dışındaki diğer yapıların yüzde değerleri Şekil 11 de 
görülmektedir. Sıcaklığın düşmesiyle tanımlı olmayan yapılar (diğer) azalırken tanımlı yapıların (fcc, bcc, hcp ve ikosahedral) sistem içerisindeki yüzdesi giderek artmaya başlamıştır. $1000 \mathrm{~K}$ kristal faz geçiş sıcaklığında bütün yapıların yüzdelerinde meydana gelen ani değişiklik Şekil 11 de açıkça görülmektedir. $300 \mathrm{~K}$ sıcaklık değerine ulaşıldığında model sistemin \% 86.2 lik bir oranda bcc birim hücreli yapılardan oluştuğu belirlenmiştir.

Bununla birlikte bu soğutma hızında bütün basınç değerleri için tanımlı olan yapıların sistem içerindeki yüzdelerinin sıcaklıkla değişimleri Şekil 12 de verilmiştir. Bütün basınç değerlerinde kristal faza döşüm sıcaklıklarında tanımlı yapıların yüzdelerindeki ani değişimler şekilden açıkça görülmektedir. Bütün basınç değerleri için $300 \mathrm{~K}$ de model sistem içerisinde bcc yapılar büyük bir orana sahipken diğer tanımlı yapıların yüzdesi oldukça düşük bir değerde görülmektedir.

Şekil 13(a-b) de $0 \mathrm{GPa}$ basınç altında $300 \mathrm{~K}$ sıcaklığında $1 \times 10^{13} \mathrm{~K} / \mathrm{s}$ ve $1 \times 10^{12} \mathrm{~K} / \mathrm{s}$ soğutma hızları için OVITO programından elde edilen atomik konumlar verilmiştir. Yeşil fcc, kırmızı hcp, mavi bcc ve sarı renkl ikosahedral yapıdaki atomları temsil ederken beyaz renkli atomlar tanımsız yapıları temsil etmektedir. $1 \times 10^{12} \mathrm{~K} / \mathrm{s}$ soğutma hızı için yapının çoğunluğunun bcc birim hücrelerden meydana geldiği açıkça görülmektedir.

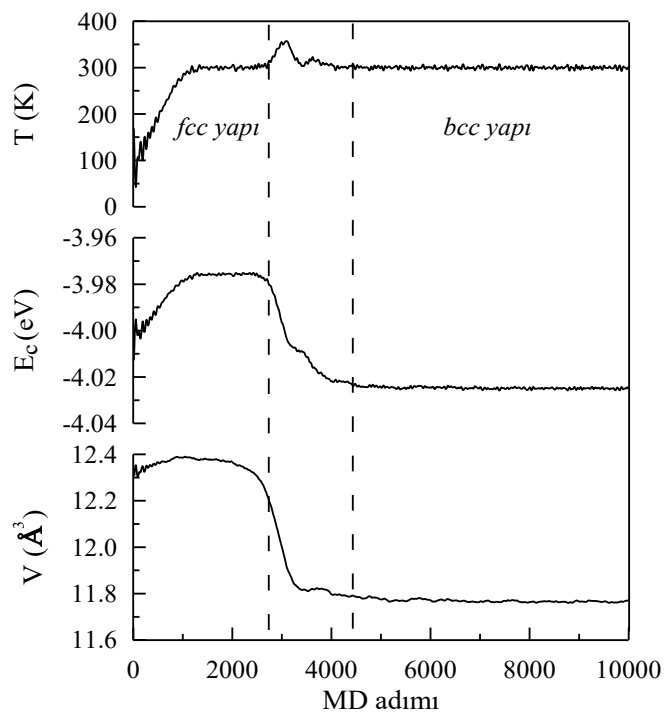

Şekil 1. Sıcaklığın birim atom başına bağlanma enerjisinin ve birim atom başına hacmin MD adımı ile değişimi

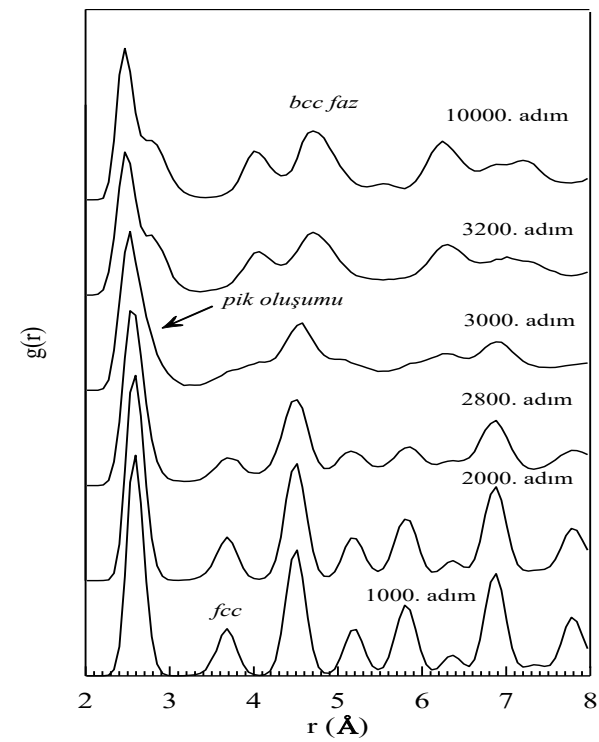

Şekil 2. $300 \mathrm{~K}$ sıcaklık değerinde ve farklı MD adımlarında elde edilmiş RDF eğrileri 


\begin{tabular}{|c|c|c|}
\hline & $\begin{array}{l}\text { BŞEÜ Fen Bilimleri Dergisi } \\
8(1), 65-77,2021\end{array}$ & $\begin{array}{r}\text { BSEU Journal of Science } \\
\text { https://doi.org/10.35193/bseufbd.834839 }\end{array}$ \\
\hline & & 2458-7575 (https://dergipark.org.tr/tr/pub/bseufbd) \\
\hline
\end{tabular}

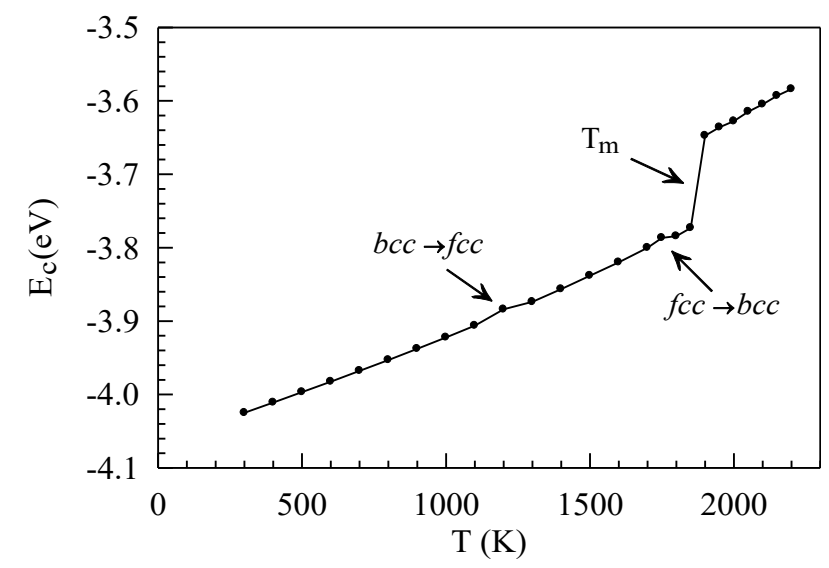

Şekil 3. Kohesif enerjinin sıcaklıkla değişimi

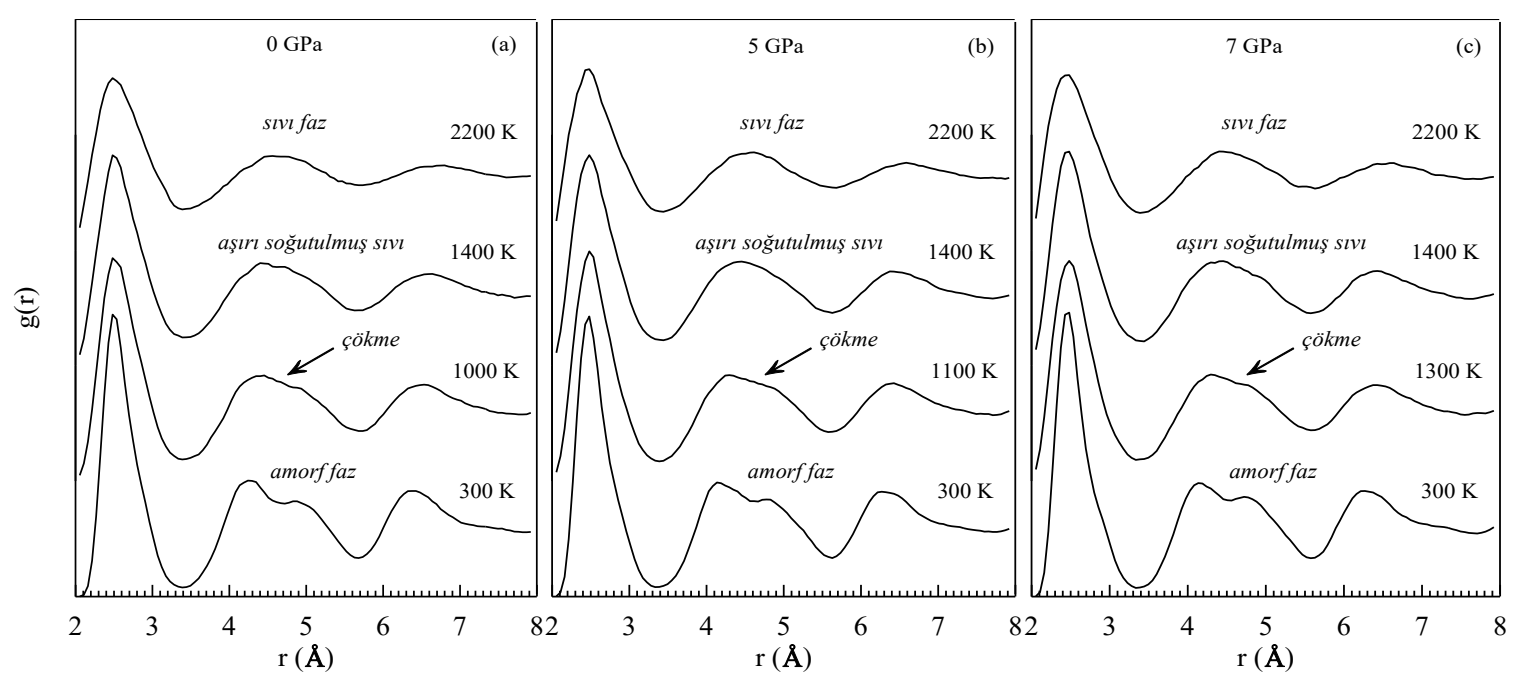

Şekil 4. $1 \times 10^{13} \mathrm{~K} / \mathrm{s}$ soğutma hızı ve $0 \mathrm{GPa}, 5 \mathrm{GPa}, 7 \mathrm{GPa}$ basınç değerleri için farklı sıcaklıklarda elde edilmiş RDF eğrileri

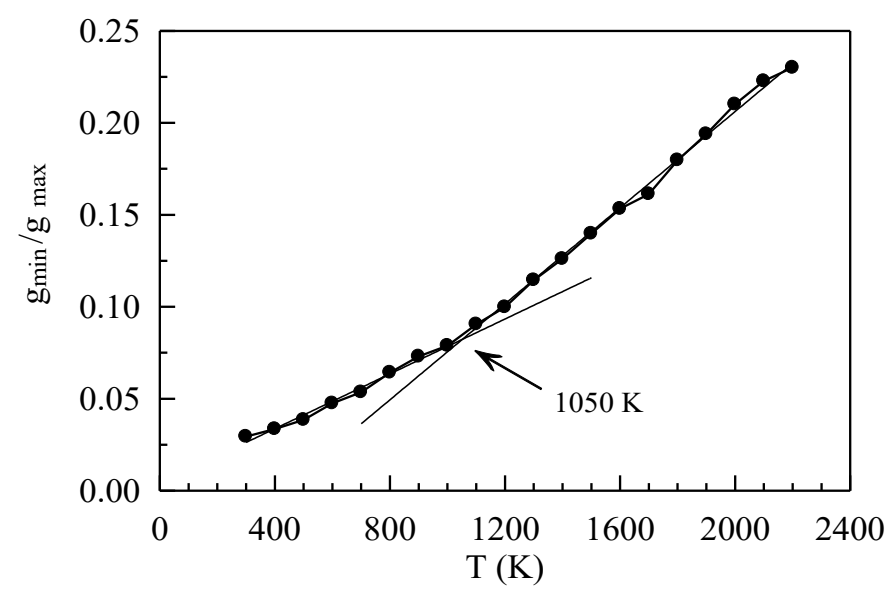

Şekil 5. $0 \mathrm{GPa}$ basınç değeri için sıcaklığa karşı $\mathrm{g}_{\min } / \mathrm{g}_{\max }$ değerinin değişimi 


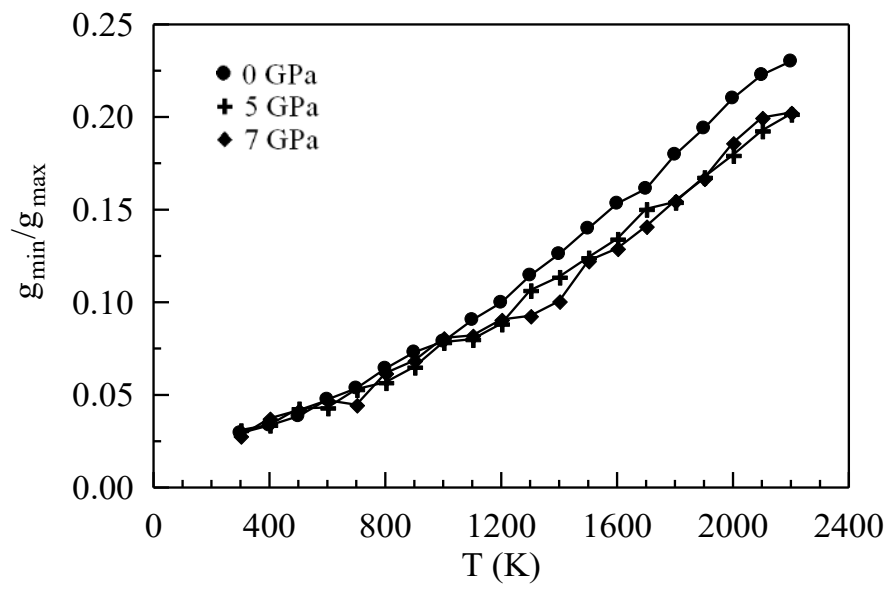

Şekil 6. Üç farklı basınç değeri için sıcaklığa karşı $\mathrm{g}_{\min } / \mathrm{g}_{\max }$ değerinin değişimi

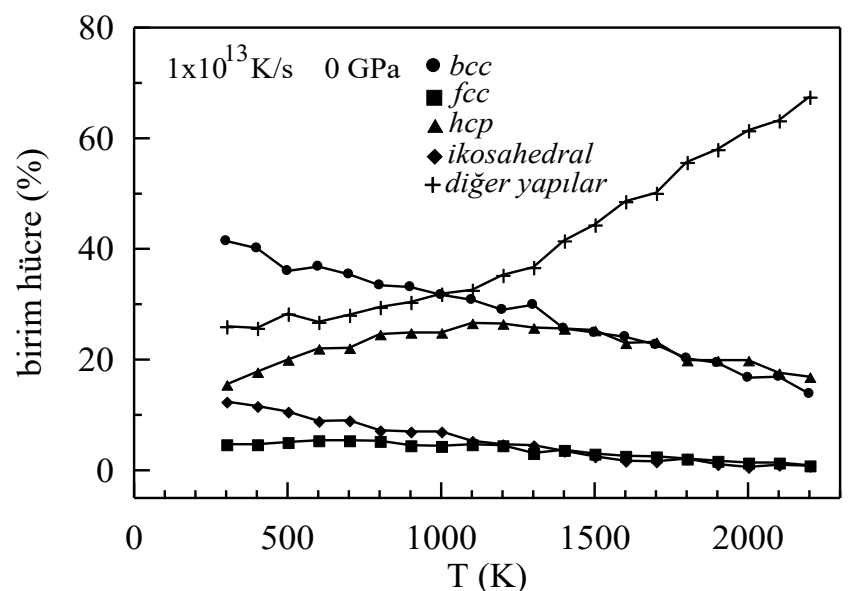

Şekil 7. 0 GPa basınç değeri için model sistemdeki farklı birim hücreli yapılarının sıcaklığa karşı değişim yüzdeleri

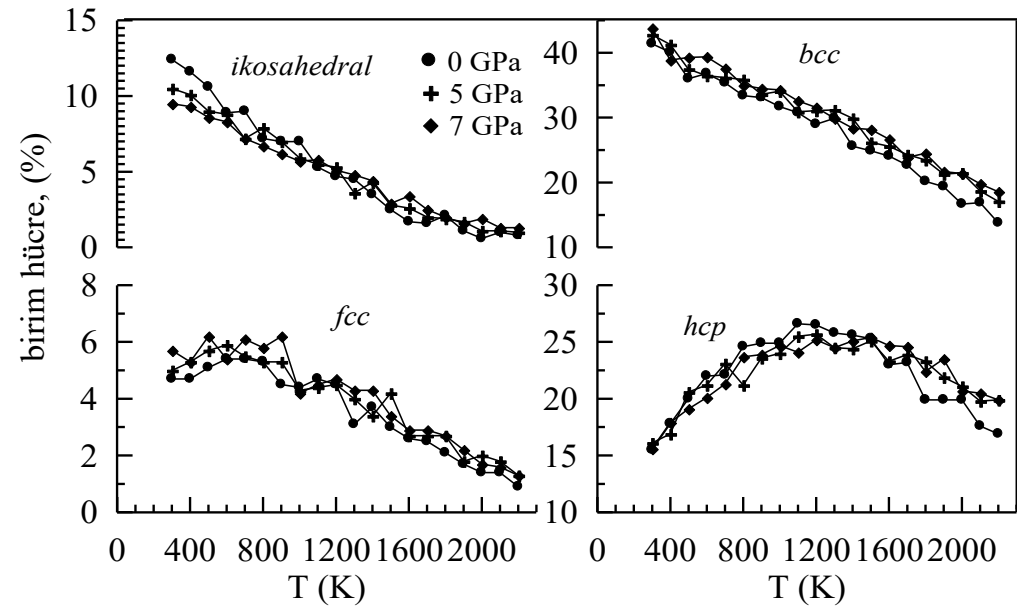

Şekil 8. Farklı basınç değerleri için model sistemdeki tanımlı farklı birim hücreli yapılarının sıcaklığa karşı değişim yüzdeleri 


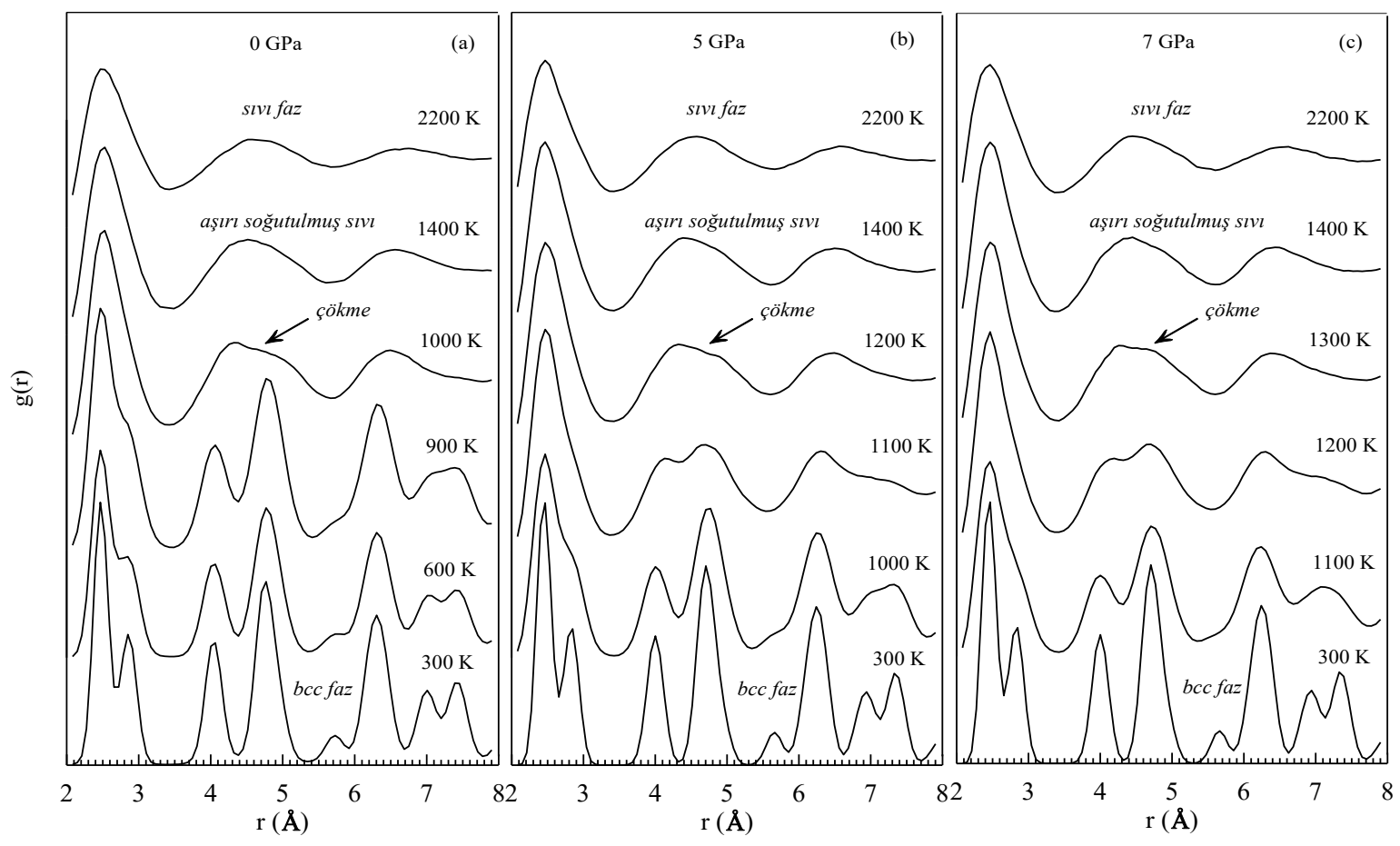

Şekil 9. $1 \times 10^{12} \mathrm{~K} / \mathrm{s}$ soğutma hızı ve $0 \mathrm{GPa}, 5 \mathrm{GPa}, 7 \mathrm{GPa}$ basınç değerleri için farklı sıcaklıklarda elde edilmiş RDF eğrileri

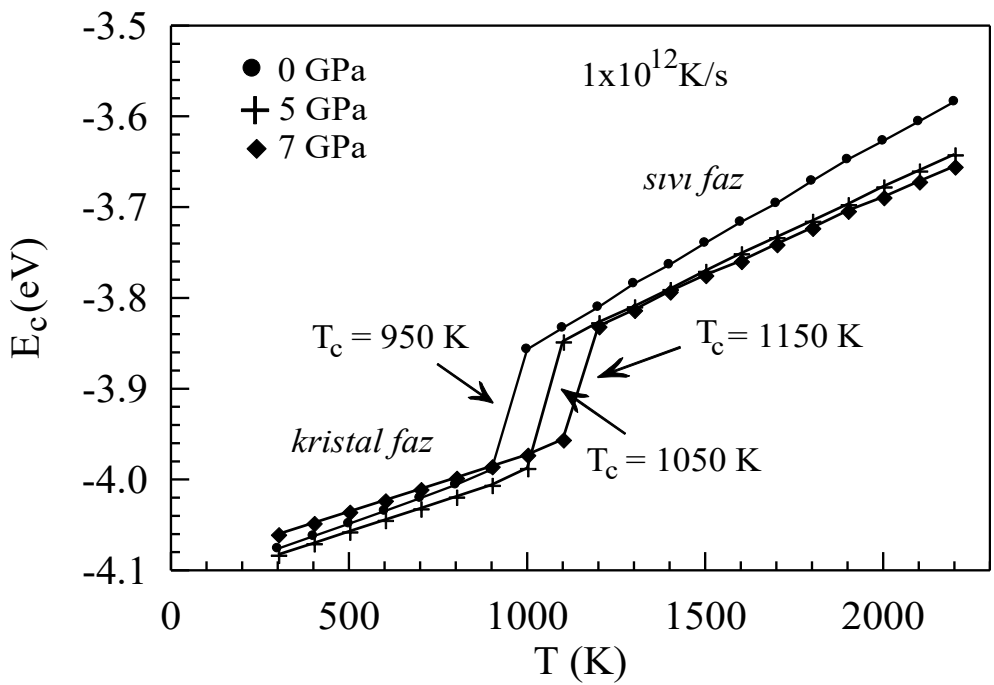

Şekil 10. Üç farklı basınç değeri için sıcaklığa karşı kohesif enerjideki değişim 


\begin{tabular}{|c|c|c|}
\hline & $\begin{array}{l}\text { BŞEÜ Fen Bilimleri Dergisi } \\
8(1), 65-77,2021\end{array}$ & $\begin{array}{r}\text { BSEU Journal of Science } \\
\text { https://doi.org/10.35193/bseufbd.834839 }\end{array}$ \\
\hline & & 2458-7575 (https://dergipark.org.tr/tr/pub/bseufbd) \\
\hline
\end{tabular}

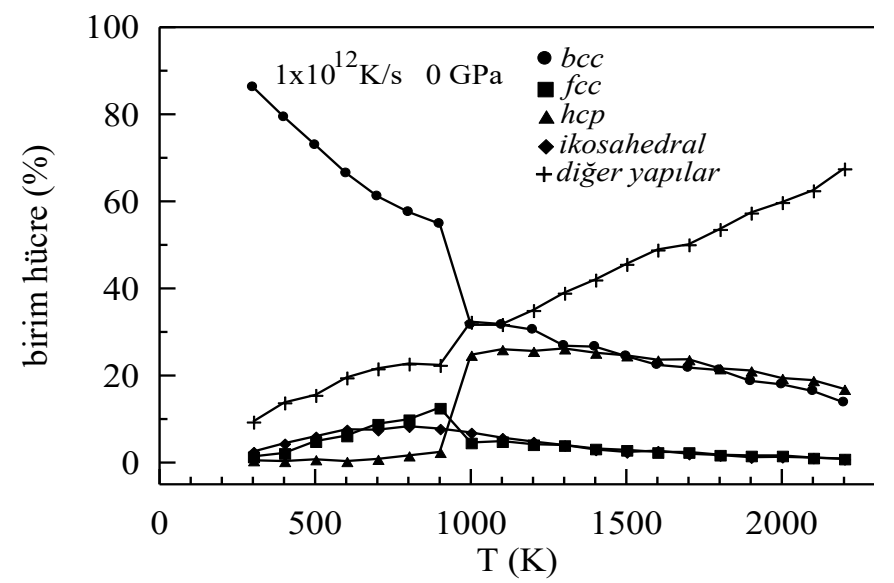

Şekil 11. 0 GPa basınç değeri için model sistemdeki farklı birim hücreli yapılarının sıcaklı̆̆a karşı değişim yüzdeleri

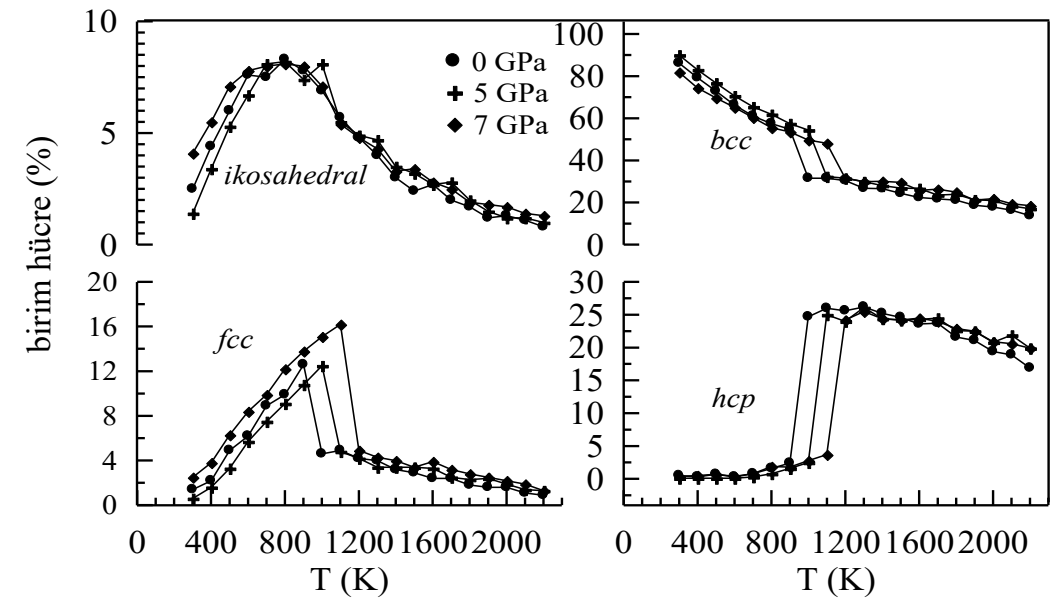

Şekil 12. $1 \times 10^{12} \mathrm{~K} / \mathrm{s}$ soğutma hızı ve farklı basınç değerlerinde model sistemdeki tanımlı farklı birim hücreli yapılarının sıcaklığa karşı değişim yüzdeleri

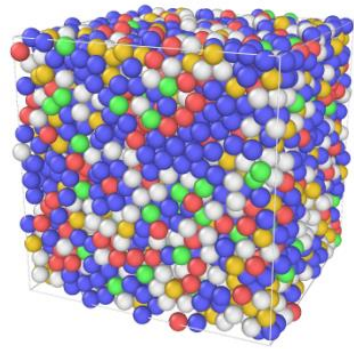

(a)

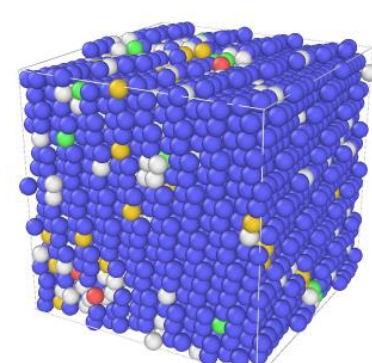

(b)

Şekil 13. $0 \mathrm{GPa}$ basınç altında $300 \mathrm{~K}$ sıcaklığında (a) $1 \times 10^{13} \mathrm{~K} / \mathrm{s}$ ve (b) $1 \times 10^{12} \mathrm{~K} / \mathrm{s}$ soğutma hızları için elde edilen atomik görüntüler. Yeşil fcc, kırmızı hcp, mavi bcc, sarı ikosahedral yapıdaki atomları temsil ederken beyaz atomlar tanımsız yapıları temsil etmektedir 


\section{SONUÇLAR}

Bu çalışmada atomlar arası etkileşmelerin Gömülmüş atom metodu ile belirlendiği sıvı Fe model sistemi üç farklı basınç değeri altında, $1 \times 10^{13} \mathrm{~K} / \mathrm{s}$ ve $1 \times 10^{12} \mathrm{~K} / \mathrm{s}$ soğutma hızları ile soğutularak molekülek dinamik yöntemiyle incelendi. $1 \times 10^{13} \mathrm{~K} / \mathrm{s}$ soğutma hızı için bütün basınç değerlerinde yapının amorf fazda olduğu ve camsı geçiş sıcaklıklarının artan basınçla arttığı belirlendi. A-J yöntemi ile yapılan analizlerde her bir atomun etrafındaki bölgesel atomik yerleşimlerin ağırlıklı olarak kristal benzeri (quasi-krsital) yapılarda olduğu ve camsı geçişin kristal benzeri atomların uzun mesafelerde bir araya gelmesinden oluştuğu ifade edildi. $1 \times 10^{12} \mathrm{~K} / \mathrm{s}$ soğutma hızı için üç basınç değeri içinde soğutma işleminin sonunda yapının kristal fazda olduğu ve artan basıncın kristal yapıya geçiş sıcaklığını da arttırdı̆̆ı belirlendi.

\section{KAYNAKLAR}

[1] Zhang, Y. \& Jiang, S. (2018). Atomistic mechanisms for temperature-induced crystallization of amorphous copper based on molecular dynamics simulation. Computational Materials Science, 151, 25-33.

[2] Giang, N. H. \& Van Hoang, V. (2021). Influences of cooling rate on formation of amorphous germanene. Physica E: Low-dimensional Systems and Nanostructures Volume, 126, 114492.

[3] Ghaemi, M. \& Tavakoli, R. (2020). Universal correlation between the thermodynamic potentials and some physical quantities of metallic glasses as a function of cooling rate during molecular dynamics simulation. Journal of Non-Crystalline Solids, 536, 119999.

[4] Samiri, A., Khmich, A., Haouas, H., Hassani, A. \& Hasnaoui, A. (2020). Structural and mechanical behaviors of $\mathrm{Mg}-\mathrm{Al}$ metallic glasses investigated by molecular dynamics simulations. Computational Materials Science, $184,109895$.

[5] Cong, H. R., Bian, X. F., Zhang, J. X. \& Li, H. (2002). Structure properties of Cu • Ni alloys at the rapid cooling rate using embedded-atom method. Materials Science and Engineering: A, 326(2), 343-347.

[6] Qi, L., Zhang, H. F., Hu, Z. Q. \& Liaw, P. K. (2004). Molecular dynamic simulation studies of glass formation and atomic-level structures in Pd-Ni alloy. Physics Letters A, 327(5-6), 506-511.

[7] Wang, W. H., Dong, C. \& Shek, C. H. (2004). Bulk metallic glasses. Materials Science and Engineering: R: Reports, 44(2-3), 45-89.

[8] Qi, L., Zhang, H. F. \& Hu, Z. Q. (2004). Molecular dynamic simulation of glass formation in binary liquid metal: $\mathrm{Cu}-\mathrm{Ag}$ using EAM. Intermetallics, 12(10-11), 1191-1195.

[9] Ozgen, S. \& Duruk, E. (2004). Molecular dynamics simulation of solidification kinetics of aluminium using Sutton-Chen version of EAM. Materials Letters, 58(6), 1071-1075.

[10] Schroers, J., Pham, Q., Peker, A., Paton, N. \& Curtis, R. V. (2007). Blow molding of bulk metallic glass. Scripta Materialia, 57(4), 341-344.

[11] Laws, K. J., Gun, B. \& Ferry, M. (2006). Effect of die-casting parameters on the production of high quality bulk metallic glass samples. Materials Science and Engineering: A, 425(1-2), 114-120.

[12] Busch, R., Kim, Y. J. \& Johnson, W. L. (1995). Thermodynamics and kinetics of the undercooled liquid and the glass transition of the Zr41. 2Ti13. 8Cu12. 5Ni10. 0Be22. 5 alloy. Journal of applied physics, 77(8), 40394043 .

[13] Luzzi, D. E. \& Meshii, M. (1986). Criteria for the amorphisation of intermetallic compounds under electron irradiation. Scripta metallurgica, 20(6), 943-948.

[14] Inoue, A. \& Takeuchi, A. (2011). Recent development and application products of bulk glassy alloys. Acta Materialia, 59(6), 2243-2267.

[15] Strutt, P. R., Nowotny, H., Tuli, M. \& Kear, B. H. (1978). Laser surface melting of high speed tool steels. Materials Science and Engineering, 36(2), 217-222. 
[16] Karewar, S., Sietsma, J. \& Santofimia, M. J. (2018). Effect of pre-existing defects in the parent fcc phase on atomistic mechanisms during the martensitic transformation in pure Fe: A molecular dynamics study. Acta Materialia, 142, 71-81.

[17] Singh, S. B. (2012). Mechanisms of bainite transformation in steels. In Phase Transformations in Steels. $385-$ 416.

[18] Porter, D. \& Easterling, K. (1992). Precipitation in Age Hardening Alloys. Phase Transformations in Metals and Alloys, 2nd ed., Chapman and Hall, London, UK.

[19] Pepperhoff, W. \& Acet, M. (2001). The magnetism of iron. In Constitution and Magnetism of Iron and its Alloys, 15-55. Springer, Berlin, Heidelberg.

[20] Pereloma, E. \& Edmonds, D. V. (Eds.). (2012). Phase transformations in steels: Diffusionless transformations, high strength steels, modelling and advanced analytical techniques. Elsevier.

[21] Haasen, P. (2013). Physikalische metallkunde. Springer-Verlag.

[22] Entel, P., Meyer, R., Kadau, K., Herper, H. C. \& Hoffmann, E. (1998). Martensitic transformations: firstprinciples calculations combined with molecular-dynamics simulations. The European Physical Journal BCondensed Matter and Complex Systems, 5(3), 379-388.

[23] Porter, D. \& Easterling, K. (1992). Precipitation in Age Hardening Alloys. Phase Transformations in Metals and Alloys, 2nd ed.; Chapman and Hall: London, UK..

[24] Pepperhoff, W. \& Acet, M. (2001). The magnetism of iron. In Constitution and Magnetism of Iron and its Alloys. 15-55. Springer, Berlin, Heidelberg.

[25] Pereloma, E. \& Edmonds, D. V. (Eds.). (2012). Phase transformations in steels: Diffusionless transformations, high strength steels, modelling and advanced analytical techniques. Elsevier.

[26] Lee, B. J., Shim, J. H. \& Baskes, M. I. (2003). Semiempirical atomic potentials for the fcc metals Cu, Ag, $\mathrm{Au}, \mathrm{Ni}, \mathrm{Pd}, \mathrm{Pt}, \mathrm{Al}$, and $\mathrm{Pb}$ based on first and second nearest-neighbor modified embedded atom method. Physical Review B, 68(14), 144112.

[27] Tateyama, S., Shibuta, Y., Kumagai, T. \& Suzuki, T. (2011). A molecular dynamics study of bidirectional phase transformation between bcc and fcc iron. ISIJ international, 51(10), 1710-1716.

[28] Lee, T., Baskes, M. I., Valone, S. M. \& Doll, J. D. (2012). Atomistic modeling of thermodynamic equilibrium and polymorphism of iron. Journal of Physics: Condensed Matter, 24(22), 225404.

[29] Finnis, M. W. \& Sinclair, J. E. (1984). A simple empirical N-body potential for transition metals. Philosophical Magazine A, 50(1), 45-55.

[30] Johnson, R. A. \& Oh, D. J. (1989). Analytic embedded atom method model for bcc metals. Journal of Materials Research, 4(5), 1195-1201.

[31] Pelaz, L., Marqués, L. A., Aboy, M., López, P. \& Barbolla, J. (2005). Atomistic modeling of dopant implantation and annealing in Si: damage evolution, dopant diffusion and activation. Computational materials science, 33(1-3), 92-105.

[32] Shao, Y., Clapp, P. C. \& Rifkin, J. A. (1996). Molecular dynamics simulation of martensitic transformations in NiAI. Metallurgical and Materials Transactions A, 27(6), 1477-1489.

[33] Daw, M. S. \& Hatcher, R. D. (1985). Application of the embedded atom method to phonons in transition metals. Solid state communications, 56(8), 697-699.

[34] Voter, A. F. \& Chen, S. P. (1986). Accurate interatomic potentials for Ni, Al and Ni3Al. MRS Online Proceedings Library (OPL), 82.

[35] Finnis, M. W. \& Sinclair, J. E. (1984). A simple empirical N-body potential for transition metals. Philosophical Magazine A, 50(1), 45-55. 
[36] Sutton, A. P. \& Chen, J. (1990). Long-range finnis-sinclair potentials. Philosophical Magazine Letters, 61(3), 139-146.

[37] Parrinello, M. \& Rahman, A. (1980). Crystal structure and pair potentials: A molecular-dynamics study. Physical review letters, 45(14), 1196.

[38] Parrinello, M. \& Rahman, A. (1981). Polymorphic transitions in single crystals: A new molecular dynamics method. Journal of Applied physics, 52(12), 7182-7190.

[39] LAMMPS Molecular Dynamics Simulator (2020). Molecular Dynamics Simulator. http://lammps.sandia.gov/.LAMMPS, (10.09.2020).

[40] Voter, A. F. \& Chen, S. P. (1986). Accurate interatomic potentials for Ni, Al and Ni3Al. MRS Online Proceedings Library (OPL), 82.

[41] Finnis, M. W. \& Sinclair, J. E. (1984). A simple empirical N-body potential for transition metals. Philosophical Magazine A, 50(1), 45-55.

[42] Etesami, S. A. \& Asadi, E. (2018). Molecular dynamics for near melting temperatures simulations of metals using modified embedded-atom method. Journal of Physics and Chemistry of Solids, 112, 61-72.

[43] Chamati, H., Papanicolaou, N. I., Mishin, Y. \& Papaconstantopoulos, D. A. (2006). Embedded-atom potential for Fe and its application to self-diffusion on Fe (1 0 0). Surface Science, 600(9), 1793-1803.

[44] Mendelev, M. I., Han, S., Srolovitz, D. J., Ackland, G. J., Sun, D. Y. \& Asta, M. (2003). Development of new interatomic potentials appropriate for crystalline and liquid iron. Philosophical magazine, 83(35), 3977-3994.

[45] Ding, S., Tian, Y., Jiang, Z. \& He, X. (2015). Molecular dynamics simulation of joining process of Ag-Au nanowires and mechanical properties of the hybrid nanojoint. AIP Advances, 5(5), 057120.

[46] Erhart, P., Marian, J. \& Sadigh, B. (2013). Thermodynamic and mechanical properties of copper precipitates in $\alpha$-iron from atomistic simulations. Physical Review B, 88(2), 024116.

[47] Ackland, G. J. \& Jones, A. P. (2006). Applications of local crystal structure measures in experiment and simulation. Physical Review B, 73(5), 054104.

[48] Rigby, M., Maitland, G. C., Smith, E. B. \& Wakeham, W. A. (1986). The forces between molecules. (Oxford Science Publications), Clarendon Press, 232.

[49] Engin, C. \& Urbassek, H. M. (2008). Molecular-dynamics investigation of the fcc $\rightarrow$ bcc phase transformation in Fe. Computational materials science, 41(3), 297-304.

[50] Karimi, M., Stapay, G., Kaplan, T. \& Mostoller, M. (1997). Temperature dependence of the elastic constants of Ni: reliability of EAM in predicting thermal properties. Modelling and Simulation in Materials Science and Engineering, 5(4), 337.

[51] Weissbach, W. \& Bleyer, U. Materials science and materials testing. 11. rev. ed. Werkstoffkunde und Werkstoffpruefung. Germany, 389.

[52] Schuh, C. A., Hufnagel, T. C. \& Ramamurty, U. (2007). Mechanical behavior of amorphous alloys. Acta Materialia, 55(12), 4067-4109.

[53] Shimojo, F., Hoshino, K. \& Zempo, Y. (2002). Intermediate-range order in liquid and amorphous As2S3 by ab initio molecular-dynamics simulations. Journal of non-crystalline solids, 312, 388-391.

[54] Stukowski, A. (2009). Visualization and analysis of atomistic simulation data with OVITO-the Open Visualization Tool. Modelling and Simulation in Materials Science and Engineering, 18(1), 015012.

[55] Abraham, F. F. (2015). The local atomic packing of a single-component glass is quasi-crystalline. arXiv preprint arXiv:1504.05751. 